\title{
How to Remove a Bent Intramedullary Nail from Long Bones
}

\author{
Seyed Reza Habibzade Shojaei* \\ Orthopedic Surgeon, Faculty of Medicine, Mashhad University of Medical Sciences, Iran
}

Submission: February 07, 2020; Published: February 25, 2020

*Corresponding author: Seyed Reza Habibzade Shojaei, Orthopedic Surgeon, Faculty of Medicine, Mashhad University of Medical Sciences, Mashhad, Iran

\section{Abstract}

The gold standard treatment for femoral, tibial and humeral shaft fractures in most circumstances is intramedullary nailing. Sometimes the nail continuity fails before a complete union, rarely the nail construct becomes bend due to high energy trauma. These circumstances are big challenges for orthopaedic surgeons. We are going to have a mini review for this condition and available technique in the literature.

Keywords: Long bone fractures; Bent intramedullary; Trauma

\section{Introduction}

The gold standard of treatment in long bone shaft fractures, except forearm bones, is intramedullary nailing [1-3]. Sometimes the intramedullary nail becomes bent, usually due to non-union. The other cause for bent intramedullary nail is severe trauma. Extraction of the bent intramedullary nail is a challenging circumstance for orthopedic surgeons. In the literature, most articles are about femoral shaft fractures [4-6]. We are going to review available methods to extract a bent intramedullary nail.

\section{Discussion}

Usually, intramedullary failure occurs due to nail construct fatigue, this condition is the result of microtraumas in especial conditions such as severe comminution. Sometimes the intramedullary construct continuity fails due to severe trauma [7], in this circumstances the nail usually becomes bend. Bent intramedullary extraction is easier than broken intramedullary extraction [8].

One method to extract the nail is to extract it as a similar method like a straight nail. This method can be used when the angulation in the tibia or femur is less than 20 degrees. Anterolateral bowing in the femoral medullary canal and large proximal canal in the tibia makes it possible to extract the nail in this condition [9]. The most ideal case to use the standard extraction technique is a fine titanium nail in a femur with anterolateral banding or tibia with a posterior apex, both less than 20-degree angulation. The second method is done by two-step at first by the use of perineal post straight the nail to the normal angulation and thereafter extract the nail by the standard method [10]. For distal and proximal fractures this method can cause a soft tissue injury due to a short lever arm, therefore, it needs excessive force. Extra fractures can occur in this condition especially in an undiagnosed longitudinal crack and osteoporotic bones [11]. This technique is not recommended in anteroposterior angulation because of the high risk of vessel injury [12].

The third technique is to open the site of the fracture to weaken the nail with drilling. The Text step is to extract the nail as a straight nail. This technique has some disadvantages. One disadvantage is debris Formation; therefore, the site of fracture should be lavaged completely. The second disadvantage is the possibility to cause heat injury due to high temperature the nail and drill, the solution for this condition is to down the temperature by a normal serum solution lavage [12-15].

The next technique is to extract the nail by cutting the nail by a saw dental drill high-speed burr $[16,17]$. This technique with saw and drill has some disadvantages include: heat burn, debris formation In this technique, continuous irrigation is mandatory to prevent heat damage and debris formation [18]. After cutting the nail the proximal part of the nail extracted as a straight nail with a similar technique. The distal part should be extracted through the fracture site. An alternative technique, which in my opinion is to extract the nail after cutting the nail in the fracture site. In this technique, we can cut the nail without debris and excessive heat 
formation. The last technique discussed in the literature is to use a femoral plate to straighten the nail and extract it by the standard method. This technique is reported only in femoral nails an can be used in a minimally invasive manner $[17,19]$.

\section{Conclusion}

There are different methods in the literature to extract a bent nail, but the most important factor to choose a technique is surgeon familiarity and preference for each technique.

\section{Conflict of Interest}

There was no conflict of interest.

\section{References}

1. Wali MG, Baba AN, Latoo IA, Bhat NA, Baba OK, et al. (2014) Internal fixation of shaft humerus fractures by dynamic compression plate or interlocking intramedullary nail: a prospective, randomised study. Strategies Trauma Limb Reconstr 9(3): 133-140.

2. Blachut PA, O'Brien PJ, Meek RN, Broekhuyse HM et al., Interlocking intramedullary nailing with and without reaming for the treatment of closed fractures of the tibial shaft. A prospective, randomized study. J Bone Joint Surg Am 79(5): 640-646.

3. Wild M, Gehrmann S, Jungbluth P, Hakimi M, Thelen S et al. (2010) Treatment strategies for intramedullary nailing of femoral shaft fractures. Orthopedics 33(10): 726.

4. Sonanis SV, Lampard AL, Kamat N, Shaikh MR, Beard DJ et al. (2007) A simple technique to remove a bent femoral intramedullary nail and broken interlocking screw. J Trauma 63(2): 435-438.

5. Nicholson P, J Rice, J Curtin (1998) Management of a refracture of the femoral shaft with a bent intramedullary nail in situ. Injury 29(5): 393 394.

6. Singh R, Sharma AK, Kiranpreet (2004) An innovative technique to cut and extract loose bent Kuntscher nail. Indian J Med Sci 58(10): 439441.

7. Bek D, Demiralp B, Tunay S, Sehirlioğlu A, Ateşalp AS, et al. (2008) Removal of a bent inflatable femoral nail: a case report. Acta Orthop Traumatol Turc 42(3): 211-213.
8. Shen PC, Chen JC, Huang PJ, Lu CC, Tien YC, et al. (2011) A novel technique to remove bent intramedullary nail. J Trauma 70(3): 755758.

9. Yip KM, Leung KS (1996) Treatment of deformed tibial intramedullary nail: report of two cases. Journal of orthopaedic trauma 10(8): 580583.

10. Patterson RH, Ramser JR Jr. (1991) Technique for treatment of a bent Russell-Taylor femoral nail. J Orthop Trauma 5(4): 506-508.

11. Aggerwal S, Soni A, Saini UC, Gahlot N et al. (2011) Removal of a bent tibial intramedullary nail: a rare case report and review of the literature. Chin J Traumatol 14(2): 107-110.

12. Heffernan MJ, Leclair W, Li X (2012) Use of the f-tool for the removal of a bent intramedullary femoral nail with a sagittal plane deformity. Orthopedics 35(3): e438-441.

13. Apivatthakakul T, S Chiewchantanakit (2001) Percutaneous removal of a bent intramedullary nail. Injury 32(9): 725-726.

14. Ohtsuka H, Yokoyama K, Tonegawa M, Higashi K, Itoman M et al. (2001) Technique for removing a bent intramedullary femoral nail: a case report. J Orthop Trauma 15(4): 299-301.

15. Park J, Yang KH Yang (2012) Removal of a bent nail after refracture of the femoral shaft. Injury 43(7): 1209-1211.

16. Kelsch G, Kelsch R, Ulrich C (2003) Unreamed tibia nail (UTN) bending: case report and problem solution. Arch Orthop Trauma Surg 123(10): 558-562.

17. Kose O, Guler F, Kilicaslan OF, May H, Yuksel HY (2016) Removal of a bent intramedullary nail in lower extremity: report of two cases and review of removal techniques. Arch Orthop Trauma Surg 136(2): 195202.

18. Bicici V (2013) Difficult revision of a bent kuntscher nail: case report. Ank Med J 13(1): 40-42.

19. Kritsaneephaiboon A, B Tangtrakulwanich, K Maliwankul (2012) A novel minimally invasive technique for removal of a bent femoral intramedullary nail. Inj Extra 43(12): 157-162.

Your next submission with Juniper Publishers will reach you the below assets

- Quality Editorial service

- Swift Peer Review

- Reprints availability

- E-prints Service

- Manuscript Podcast for convenient understanding

- Global attainment for your research

- Manuscript accessibility in different formats ( Pdf, E-pub, Full Text, Audio)

- Unceasing customer service

Track the below URL for one-step submission https://juniperpublishers.com/online-submission.php 